\title{
ORIGEM E EVOLUÇÃO DA IMAGEM DE CARONTE NA GRÉCIA ANTIGA: ANÁLISE DE ICONOGRAFIA
}

\author{
JASMIM DRIGO* \\ Universidade de São Paulo
}

Resumo. Diferentes representações de uma divindade ctônica parecem apontar para diferentes concepções de morte, e as diferenças nas representações de Caronte corroboram essa perspectiva. Os lécitos de fundo branco apresentam um barqueiro bem distinto dos vasos de figuras negras, o que leva a crer que cada tipo de iconografia tinha sua própria função religiosa e social.

Palavras-chave. Caronte; lécitos de fundo branco; vasos de figuras negras; rituais fúnebres; Grécia Antiga.

D.O.I. 10.11606/issn.2358-3150.v19i1p123-131

A Figura de UM bARQUEIRo QUE ATRAVESSA OS MORTOS NO SUBMUNDO É REcorrente em diversas mitologias antigas: mesopotâmios, nórdicos, etruscos, gregos, romanos e outros povos possuíam esse personagem em seus mitos e ritos. O barqueiro grego Caronte é um dos exemplos mais conhecidos desde a Antiguidade, além de ter sido mencionado, apropriado e transformado por diversos povos e artistas posteriormente.

As representações de Caronte na Grécia Antiga (do séc. vi a. C. ao séc. II d.C.) podem ser separadas basicamente em dois tipos: literárias e iconográficas. Nas representações literárias, Caronte aparece em trechos de Aristófanes, Eurípides, Pausânias, Luciano de Samósata e em alguns epigramas.

Neste artigo, analisar-se-á as representações iconográficas, as quais apresentam um barqueiro muito específico, diferente daquele caracterizado nos textos literários. A análise terá ênfase na comparação entre vasos de figuras negras e entre lécitos de fundo branco. $\mathrm{O}$ intuito aqui não é esgotar o tema, mas apenas apontar as principais características de cada tipo de representação.

Mestre em Letras Clássicas pela Universidade de São Paulo.

“. Artigo recebido em 05.ago.2015 e aceito para publicação em 31.out.2015. 


\section{ANÁLISE DA ICONOGRAFIA}

O lécito de fundo branco é um tipo de vaso bem demarcado no tempo e no espaço: é fruto da Atenas Clássica do séc. vi ao IV a. C., por tal razão, ele representa os ritos e costumes funerários de uma sociedade específica durante um breve período. O lécito é fundamental para a compreensão de Caronte, pois é nesse tipo de material que se encontra o maior número de representações iconográficas do barqueiro grego. O lécito de fundo branco é um objeto extremamente inovador, não apenas o conteúdo das representações é inovador, mas também a própria técnica de pintura. Beazley (1938, 3-5) explica o grande avanço que foi combinar a técnica de fundo branco à técnica de outline. A primeira consistia em pintar o vaso de cerâmica com uma fina camada de tinta branca, na qual os artistas desenhavam as figuras em vez de pintar diretamente sobre a cerâmica. A outline consistia em apenas delinear a figura, sem preenchê-la por total como antes era feito. A técnica de fundo branco foi de fato uma inovação do século vi a.C., enquanto a técnica outline já existia no século viı a.C., mas não era muito empregada. Quando os vasos de fundo branco surgem, a outline se apresenta como uma grande invenção, pois o contraste se torna maior e enfatiza as figuras.

Caronte é representado em muitos lécitos de fundo branco, mesmo antes da combinação dessa técnica com a outline. No entanto, em vasos que apresentam a combinação dessas duas técnicas, o barqueiro aparece com mais frequência, além de ser mais facilmente identificável.

Essa técnica permitia ao pintor utilizar mais cores e grafar mais detalhes. A Figura 1, em contraposição com a Figura 2, apresenta mais detalhes: a túnica apresenta dobras, o barqueiro possui sobrancelhas, o cabelo e a barba possuem mais ondulações; além disso, há mais possibilidades de cores, ainda hoje se pode ver pelo menos duas cores, vermelho e preto.

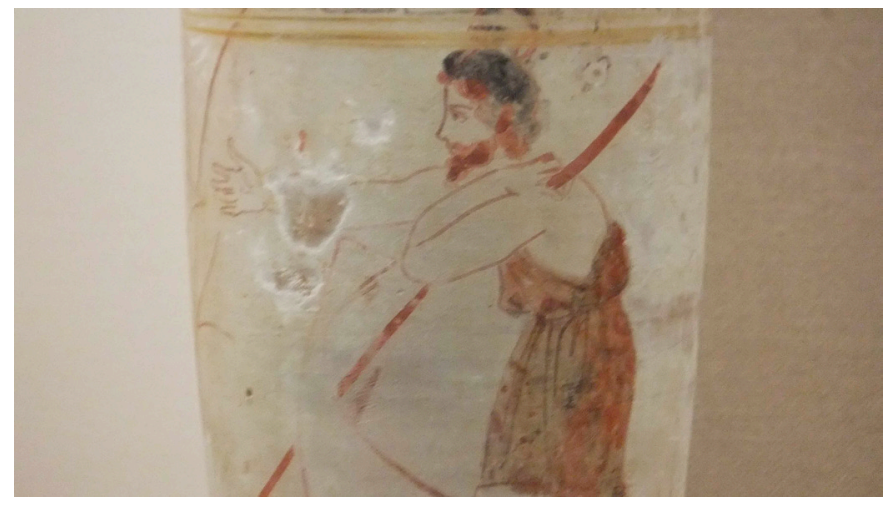

Figura 1.

Caronte

estendendo a mão. Vaso atribuído ao Pintor de Reed; feito em Atenas entre 420-410 a.C. Gr 1874.11-10.4 BM Cat Vases D61. 


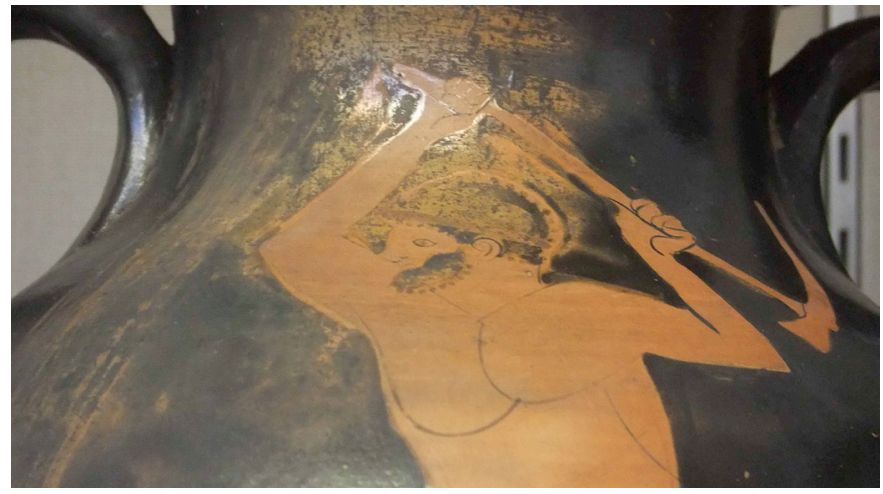

Figura 2.

Héracles com um machado. Vaso atribuído ao Pintor Anjo-Voador; encontrado em Camirus, tumba 143 de Fikellura; datado de aprox. 480 a.C. GR 1864.10-7.120 (E364).

No século v a.C., o uso do fundo branco se restringe, basicamente, a vasos de contextos funerários, os lécitos. Beazley $(1938,3-5)$ levanta a hipótese de que, devido à fragilidade desses vasos, a técnica deixou de ser utilizada para vasos de uso cotidiano. Os lécitos, por sua vez, eram apenas utilizados para ocasiões funerárias, ou seja, ocasiões específicas; eles eram somente usados uma vez ou então deixados como oferendas nas sepulturas.

Caronte aparece em muitos dos lécitos que sobreviveram até a época atual, ele é pintado em sua barca, geralmente em pé, à espera de algum morto; com um chapéu esférico; com um comprido varejão, que parece servir mais pra guiar do que para remar; com uma túnica comum; e com uma barba espessa, porém curta.

Nos lécitos de fundo branco, a fisionomia do barqueiro nunca é assustadora ou horrível, no máximo ele é representado como um ser impaciente, à espera dos mortos. Nos lécitos de um artista específico, o Pintor ${ }^{1}$ de Caronte, o barqueiro geralmente aparece com uma fisionomia agradável e simpática.

Um exemplo bastante ilustrativo é um vaso atribuído ao Pintor de Tânatos, no qual se retrata Hermes conduzindo uma mulher até a barca de Caronte. Hermes desempenha no lécito, portanto, seu papel de condutor

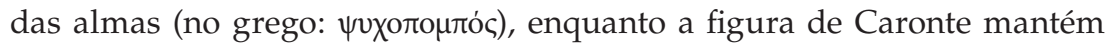
sua função de barqueiro. Ele está em sua barca esperando a falecida, pronto para partir; usa o chapéu coco, o varejão e a túnica e é um homem barbado (Figura 3).

Em algumas representações literárias, como em Alceste, Héracles e As rãs, não há detalhes sobre a fisionomia do barqueiro. Isso dificulta a apro-

\footnotetext{
${ }^{1}$ Muitos dos pintores de vasos da Grécia Antiga receberam nomes modernos por causa da imagem de algum vaso específico ou por causa da localização aonde um vaso foi encontrado, isso porque muitos vasos não apresentavam o nome do artesão na iconografia.
} 


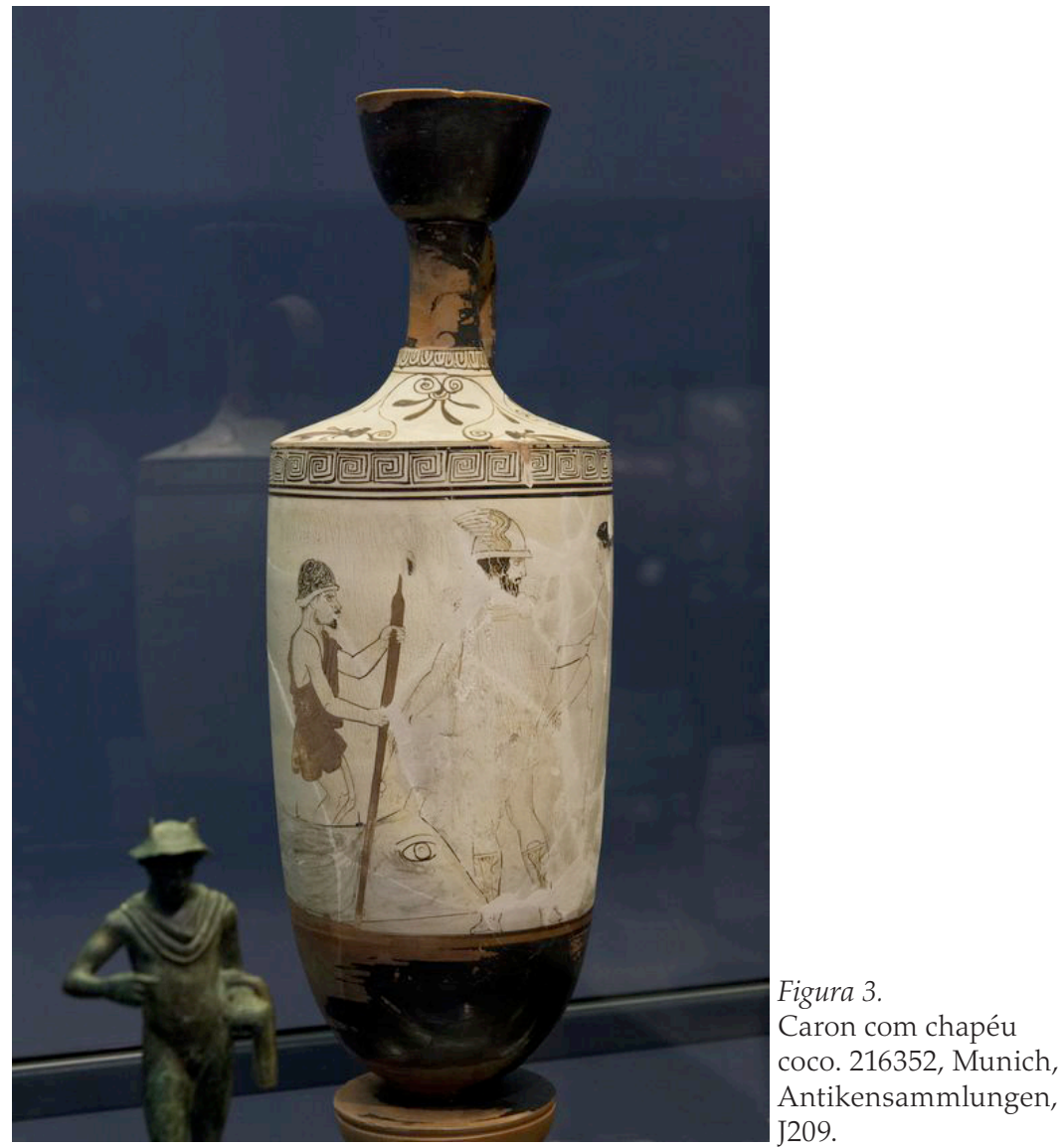

ximação entre literatura e iconografia, pois Caronte sempre é retratado de uma determinada forma nos vasos funerários: sempre aparecem elementos típicos, como a zinga e o chapéu, o que facilita a sua identificação. Por tal razão, parece difícil acreditar que certos aspectos de sua aparência, tão típicos, não seriam mencionados se a figura do barqueiro fosse exatamente a mesma nos dois tipos de arte.

O chapéu esférico de Caronte já um objeto estranho ao contexto funerário grego. Há outros chapéus arredondados na iconografia grega, no entanto, eles estão normalmente associados a contextos bélicos ou a figuras cuja principal atividade é a guerra, é o caso de Aquiles, por exemplo.

Uma curiosa exceção é um vaso de figuras negras do Pintor AnjoVoador (Figura 2), no qual Héracles surge com um chapéu esférico e um machado comprido. O herói é de fato um personagem guerreiro, mas seus 
objetos característicos são o porrete e a pele de leão, que representam a força física e remontam aos grandes feitos do herói. Nesse panorama, o chapéu perde seu sentido bélico e se torna inusitado, pois é um objeto que normalmente não se relaciona a Héracles.

A presença do machado também é curiosa, visto que essa arma não é frequente no contexto bélico, como a espada, a lança e o próprio porrete. Empunhar um machado requer força física e proximidade ao inimigo, mas na iconografia antiga esse objeto lembra mais o machado do demônio etrusco Carun, símbolo do golpe da morte. ${ }^{2}$

É possível entender a presença desses objetos na análise dos mitos nos quais Héracles figura. Em uma das versões de seus mitos, Héracles morre e depois é resgatado por Zeus, o qual concede a seu filho viver entre os deuses. Héracles é o que conheceu o Hades e retornou, talvez por isso seja possível a união singular do chapéu esférico e do machado em um herói. Ele não é uma divindade ctônica, mas já esteve perto o suficiente do mundo dos mortos para ser representado semelhante a Caronte, ou mais ainda, semelhante a Carun.

Sourvinou-Inwood $(2006,321-53)$ analisa de forma sistemática as representações de Caronte nos lécitos de fundo branco. Primeiro, a autora classifica as figuras em duas variantes: na variante $\mathrm{A}$, o barqueiro está em seu barco prestes a receber uma alma que está na margem sozinha ou acompanhada por Hermes ou por outro humano; na variante B, há uma união entre uma cena com Caronte e uma cena de visita à tumba ou uma cena com Hipnos e Tânatos carregando um cadáver.

A visita à tumba, como mostra Florenzano (1996, 75-80), era um rito costumeiro. No enterramento, oferendas eram deixadas para o morto e mesmo depois da inumação, parentes e amigos voltavam para prestar homenagens aos falecidos. Não se sabe ao certo com qual frequência esse costume era realizado, alguns dizem que a visita à tumba era feita no nono dia depois da morte, outros falam de trinta dias, outros mencionam apenas um culto anual, provavelmente nas Genésias, quando todos os mortos eram cultuados. Isso explica por que esse tema era o mais comum em lécitos.

Sourvinou-Inwood (2006, 327-38) explica que a retratação das almas se tornou mais detalhada com o passar do tempo: as únicas duas pinturas de figuras negras de Caronte mostram várias almas aladas e indistintas; as representações mais antigas em lécitos tampouco apresentam detalhes dos mortos; mas no século v e IV a. C., as almas se tornam individualizadas, é possível reconhecer mulheres, crianças e efebos. Representações de visita à tumba, por sua vez, focalizariam o mundo dos vivos, como os vivos se

${ }^{2}$ Para mais sobre o barqueiro etrusco, ver: De Ruyt 1934. 
comportam frente à morte. Por fim, cenas com Hipnos e Tânatos estariam centradas no momento do enterro e na boa morte.

A autora $(2006,334)$ observa uma característica importante das representações nas quais Caronte aparece: em nenhuma delas o barqueiro é mostrado acompanhado de homens adultos, ele sempre aparece com mulheres, crianças e jovens. A partir dessa observação, ela conclui que as cenas com Caronte apenas eram apropriadas para mulheres, adolescente e crianças, pois essas pessoas seriam as que necessitariam ser tranquilizadas no momento da morte.

Os homens adultos carregavam outro significado de boa morte, que seria a morte gloriosa em batalha. Na Atenas Clássica, todos os cidadãos mortos em guerra de forma honrosa eram homenageados em morte com funerais públicos, era a morte heroica. Em contrapartida a isso, havia a morte dos cidadãos que não guerreavam, para os quais a morte era assustadora, por isso, era necessário um apoio maior nesse momento terrível. Martin (2016) também conclui que o objetivo dessas representações era fornecer conforto para esses cidadãos, por isso os traços harmônicos.

Os dois vasos gregos de figuras negras que representam o barqueiro do mundo dos mortos são anteriores aos lécitos de fundo branco, mas em apenas algumas décadas, provavelmente do começo do século vi ou final do século v a. C..

O mais conservado é o vaso da coleção de Liebieghaus, em Frankfurt (Figura 4); nele é possível ver Caron em sua barca, rodeado de eidola. Aqui o barqueiro é representado com um chapéu arredondado e com uma barba branca, contudo em vez de um varejão, ele porta um remo comum. O que

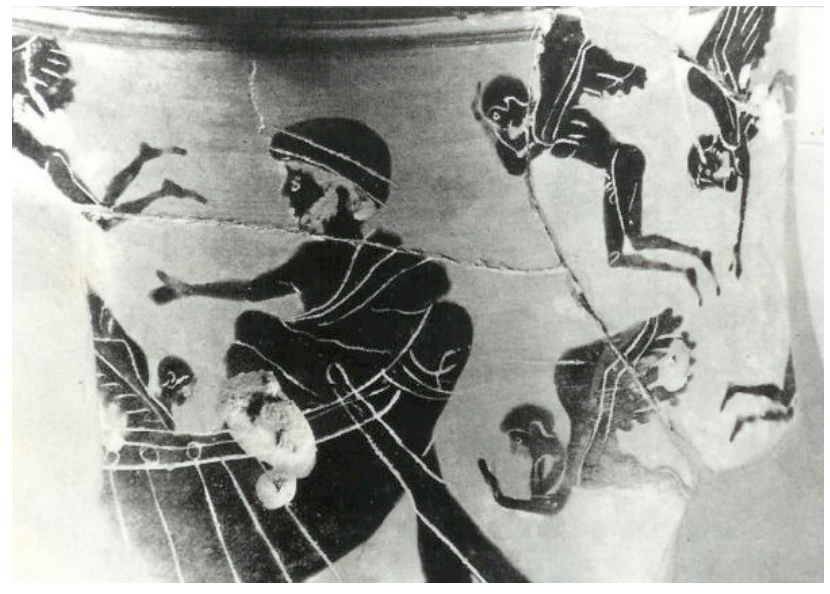

Figura 4.

Caronte com eidola. 4966, Frankfurt, Liebieghaus, 560 . 
diferencia sobretudo essa imagem das outras em lécitos é a presença de várias almas aladas em torno do barco, as eidola.

Sourvinou-Inwood $(2006,336)$ constata que a presença das eidola com Caronte apenas ocorre em dois lécitos mais antigos, além do vaso de figuras negras de Frankfurt. A partir dessa observação, a autora traça uma oposição entre as representações mais antigas e as mais recentes: as primeiras representariam figuras aladas e anônimas, enquanto as segundas representariam almas individualizadas.

A autora explica que as duas formas de representação resultam de duas maneiras diferentes de se encarar a morte. As pequenas almas aladas estão mais próximas de uma esfera mitológica e não representam pessoas reais, ou seja, a morte é vista como algo distante, é a morte do outro, a morte coletiva. Talvez por esse modelo ser mais distante da realidade, ele tenha sido descartado rapidamente.

Já as figuras de mortos individualizados se aproxima mais do mundo dos vivos. As almas são pintadas tal como os vivos, não há diferença, tanto que em muitos casos é difícil distinguir o falecido dos vivos. Geralmente essa suposição é feita com base nas atitudes ou objetos das figuras; por exemplo, a pessoa que está ao lado de uma estela é interpretada como a alma, enquanto aqueles que deixam oferendas são os vivos, mas nem sempre essa diferenciação é tão simples.

Sourvinou-Inwood $(2006,336)$ analisa a individualização do morto como uma maneira de aproximar a morte do mundo dos vivos e torná-la um pouco menos assustadora e obscura. Além disso, a memória do falecido

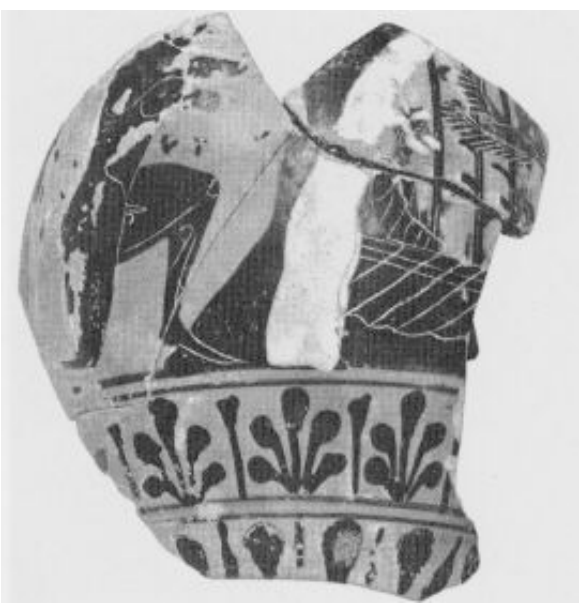

Figura 5.

Caronte (?) em fragmento. 9523, Tubingen, Eberhard-Karls-Univ., Arch. Inst., S101507A. 
se perpetua de modo mais concreto, o que pode ser visto como uma homenagem póstuma.

Apenas uma pequena parte do outro vaso sobreviveu, trata-se do fragmento de Tübingen (Figura 5). A imagem está incompleta e a interpretação é difícil, de modo que há várias possibilidades de leitura. Uma interpretação interessante é de Eliana Mugione (1995: 359); a autora enxerga no fragmento Caronte ao lado da punição de Sísifo, nessa perspectiva, o barqueiro seria um sinônimo para o próprio Hades.

A estudiosa compara a imagem com os versos do Minias citados por Pausânias $(10,28)$ : a aparência do barqueiro se assemelha à descrição do poema, Caronte é mostrado como um velho barqueiro.

\section{CONCLUSÃO}

A transformação da figura de Caronte na iconografia é considerável mesmo quando apenas alguns séculos são analisados, como é o caso desta apresentação. Pode-se observar dois momentos de representação do personagem: um mais antigo, referente ao século vi e parte do $\mathrm{v}$ a. C., no qual Caronte está relacionado à morte coletiva e anônima; e outro mais recente, referente aos séculos v e IV a. C., em que o barqueiro está ligado à morte individual.

A representação de uma figura calma e tranquilizadora seria compreensível, portanto, dada a função de Caronte de acalmar as mulheres, adolescentes e crianças no momento da morte.

\section{REFERÊNCIAS}

Beazley, J. D. 1938. Attic White Lekythoi. Londres: Oxford University Press.

De Ruyt, Franz 1934. Charun démon etrusque de la mort. Roma: Institut Historique Belge. Florenzano, Maria B. B. 1996. Nascer, viver e morrer na Grécia antiga. São Paulo: Atual Editora.

Martin, Bridget 2016. "Cold confort: winged psychai on fifth-century BC Greek funerary lekythoi". Bulletin of the Institute of Classical Studies 59:1-25.

Mugione, Eliana. 1995. "La raffigurazione di Caronte in età greca". La Parola del Passato 50(2-6):357-75.

Sourvinou-Inwood, C. 2006. 'Reading' Greek Death to the end of the Classical Period. Nova York e Oxford: Clarendon paperbacks e Oxford University Press. 


\section{$*$}

Title. Origin and evolution of Charon's image in Ancient Greece: iconographic analysis.

Abstract. Different representations of a chthonic deity seem to indicate different conceptions of death, and the differences in the representations of Charon corroborate this view. The white-ground lekythoi feature a very different ferryman from the one portrayed in black figured vases, which suggests that each type of iconography had its own religious and social function.

Keywords. Charon; white-ground lekythoi; black figured vases; funeral rites; Ancient Greece. 